\title{
Emergence Patterns of Delia radicum (Diptera: Anthomyiidae) Populations from North Carolina and New York
}

\author{
J. F. WALGENBACH, ${ }^{1}$ C. J. ECKENRODE, ${ }^{2}$ AND R. W. STRAUB ${ }^{3}$
}

Department of Entomology, North Carolina State University, Raleigh, NC 27695

\begin{abstract}
Environ. Entomol. 22(3): 559-566 (1993)
ABSTRACT Cabbage maggot, Delia radicum (L.), populations from North Carolina (Fletcher and Scaly Mountain) and New York (Geneva and Highland) were surveyed to detect differences in the emergence pattern of flies from overwintered pupae. Populations from all locations consisted of different proportions of early-and later-emerging individuals. However, populations from New York consisted predominately of early-emerging individuals ( $\geq 90 \%$ ), whereas populations from North Carolina were composed of a higher percentage of later-emerging individuals. Emergence patterns of $F_{1}$ progeny from crosses between early- and later-emerging flies from Scaly Mountain demonstrated that emergence traits were genetically controlled. $D$. radicum phenology studies in North Carolina suggested that temporal isolation of the two types was halted by an extended period of aestivation during the summer months, which subsequently allowed the two populations to interbreed during the autumn months. The relative proportion of early:late emergers appears to be unstable over time, which may be due to differential mortality factors operating when populations are temporally isolated or due to dominance or recessive factors governing earliness or lateness, or both.
\end{abstract}

KEY WORDS cabbage maggot, Delia radicum, biotypes

Cabbage maggot, Delia radicum $(\mathrm{L}$.), is an important root-infesting pest of cruciferous crops throughout much of the temperate zone of the Holarctic region. In North America, $D$. radicum is a serious pest primarily north of $40^{\circ} \mathrm{N}$ latitude (Metcalf et al. 1962). In that region there are usually three generations per season (Eckenrode \& Chapman 1972), but varying weather conditions can result in as few as two (Harris et al. 1967) or as many as four (Eckenrode \& Arn 1972). In addition, fly emergence is sometimes suppressed during the warmer summer months because of aestivation of pupae (Harris \& Svec 1966, Sears \& Dufault 1986).

In the southern United States, D. radicum is an important pest only at higher altitudes. In a study summarizing the distribution and earlyseason biology of $D$. radicum in North Carolina, Fulton (1942) concluded that this insect is injurious to cruciferous crops only above $900 \mathrm{~m}$ altitude. It was also concluded that $D$. radicum probably completed three generations per season in western North Carolina. Furthermore, adult emergence in the spring from overwintered pupae was observed to begin in late

\footnotetext{
1 Mountain Horticultural Crops Research \& Extension Center, 2016 Fanning Bridge Road, Fletcher, NC 28732.

2 Department of Entomology, New York State Agricultural Experiment Station, Cornell University, Geneva, NY 14456.

${ }^{3}$ Department of Entomology, New York State Agricultural Experiment Station, Cornell University, Highland, NY 12528.
}

March-early April and to extend to early June, with an abundance of flies emerging in late May. This protracted pattern of fly emergence (about $60 \mathrm{~d})$ from overwintered pupae, which culminated in a large emergence of flies, is in contrast to that observed in the more northern areas of North America.

These earlier studies in North Carolina (Fulton 1942) were conducted before Finch \& Collier (1983) reported $D$. radicum biotypes that varied in spring emergence patterns. Finch \& Collier (1983) found that in some areas of the United Kingdom spring emergence occurred over a relatively short period of time in April or May, whereas in other areas emergence was protracted such that many flies did not emerge until June or July. These different populations were classified as early- and late-emerging biotypes based on the timing of spring emergence. In the laboratory, biotypes could be differentiated following the cold phase of diapause development, because $>90 \%$ of the flies of the early-emerging biotype emerged from pupae within $14 \mathrm{~d}$ when held at $20^{\circ} \mathrm{C}$, whereas emergence in the lateemerging biotype was protracted and completed over a period of 60-100 d. Subsequent work by Collier et al. (1989) demonstrated that postdiapause development of early biotypes occurred after the cold phase of diapause development was completed and temperatures rose above $4.3^{\circ} \mathrm{C}$ (Collier \& Finch 1985), but late bio- 
types required an additional period at temperatures above $7^{\circ} \mathrm{C}$ before post-diapause development occurred (Collier et al. 1989). In addition, an intermediate biotype was also described that consisted of different proportions of individuals with slightly later emergence, but tending more toward the early than late spectrum of emergence (Finch et al. 1986).

Finch \& Collier (1983) also demonstrated that populations exhibiting early-, intermediate-, or late-emergence patterns could be selected within one generation from a parental population that was heterogeneous with respect to emergence. The dominance of either early- or lateemerging biotypes in various localities was presumed to be maintained by temporal, and thus reproductive, isolation (Finch et al. 1986).

North American populations of $D$. radicum have not previously been examined for the occurrence of early- or late-emerging characteristics, although early-season adult phenology in the northern United States (Schoene 1916, Eckenrode \& Arn 1972, Eckenrode \& Chapman 1972) and Canada (Harris et al. 1967, Sears \& Default 1986) suggests that these populations are predominately of the early-emerging type. In contrast, adult emergence patterns described by Fulton (1942) in North Carolina suggested that this population, at that time, was predominately of the late-emerging type. Reported here is a comparison of the emergence characteristics of D. radicum populations from New York and North Carolina, and the seasonal adult phenology of $D$. radicum in western North Carolina from 1987 to 1990 .

\section{Materials and Methods}

Survey for Early- and Late-Emerging Biotypes. D. radicum populations surveyed from North Carolina were collected at Scaly Mountain (1,218 $\mathrm{m}$ elevation) and Fletcher $(685 \mathrm{~m}$ elevation), and New York populations were collected from Geneva (240 $\mathrm{m}$ elevation) and Highland (60 $m$ elevation). At the Scaly Mountain location, diapausing pupae were collected from the roots and soil surrounding cabbage plants remaining in the fields in December from 1987 to 1990. Populations were collected at Fletcher in 1987 and 1988; at Geneva in 1987, 1988, and 1989; and from Highland in 1987 and 1989 . At the latter three locations, pupae were collected in December of each year by removing diapausing pupae from the roots and soil surrounding turnips planted in the late summer of each year. In all instances, pupae were shipped to Fletcher, NC, immediately after collection.

In the laboratory, pupae were washed, positively identified as $D$. radicum (Brooks 1951), placed in groups of $\approx 50$ into $500-\mathrm{ml}$ cups, and covered with moist sand. Pupae were incubated at $4^{\circ} \mathrm{C}$ and a photoperiod of $12: 12$ (L:D)h for a minimum of 16 wk to ensure completion of diapause development. Pupae were then placed at $20^{\circ} \mathrm{C}$ and a photoperiod of $16: 8(\mathrm{~L}: \mathrm{D}) \mathrm{h}$, and fly emergence was recorded daily. Emergence patterns were classified according to Finch et al. (1986): percentage of early emergers (percentage of flies emerging within $14 \mathrm{~d}$ ), median time for emergence $\left(T_{50}\right)$, and time elapsing between emergence of 10 and $90 \%$ of the flies $\left(T_{10-90}\right)$.

Inheritance of Early (E) and Late (L) Emergence. To determine whether early- or lateemerging traits of flies from the Scaly Mountain population were genetically controlled, crosses were made among individual male and female flies emerging from pupae collected in December 1988. To do this, both early- and lateemerging flies had to be available at the same time; thus, pupae for the late-emerging flies were removed from $4^{\circ} \mathrm{C} \approx 25 \mathrm{~d}$ before the pupae for the early-emerging flies. For all crosses, early individuals were those tlies emerging 10-12 d after removal from $4^{\circ} \mathrm{C}$, and late individuals were those flies emerging 35-40 d after removal from $4^{\circ} \mathrm{C}$. Five to eight crosses each of the following pairs were made: $E$ males $\times E$ females, $E$ males $\times \mathrm{L}$ females, $\mathrm{L}$ males $\times \mathrm{E}$ females, and $\mathrm{L}$ males $\times \mathrm{L}$ females.

Individual pairs of male and female flies were caged in 32 by 32 mesh Lumite screen (Chicopee, Gainesville, GA) cages ( $8 \mathrm{~cm}$ diameter by $15 \mathrm{~cm}$ high) containing two food sources ( $10 \%$ sucrose solution and a 1:1 mixture of brewers yeast + yeast hydroysate [ICN Biochemicals, Cleveland, $\mathrm{OH}$ ], and a small dish $(9 \mathrm{~cm}$ diameter by $2 \mathrm{~cm}$ high) containing a piece of rutabaga on moist sand for oviposition. Eggs were collected from each pair at 2 -d intervals, held at $4^{\circ} \mathrm{C}$ until females no longer oviposited, and then washed onto slices of rutabaga and placed at $12^{\circ} \mathrm{C}$ with a photoperiod of $12: 12$ (L:D)h for $70 \mathrm{~d}$ to induce diapause. Diapausing pupae were then collected from the rutabaga, stored at $4^{\circ} \mathrm{C}$ and a photoperiod of 8:16 (L:D)h for a minimum of $16 \mathrm{wk}$ to complete diapause development, and then placed at $20^{\circ} \mathrm{C}$ and a photoperiod of $16: 8(\mathrm{~L}: \mathrm{D}) \mathrm{h}$ and fly emergence recorded daily. Although $\mathrm{Col}$ lier \& Finch (1983) reported that 20 wk was necessary for completion of diapause development for $D$. radicum populations in England, flies emerged from $80 \%$ of pupae collected in our studies, indicating that our population required a shorter cold treatment than the Collier \& Finch (1983) population for completion of diapause development.

Emergence data (percentage of early emergers, $T_{50}$, and $T_{10-90}$ ) for progeny from each cross were calculated using all individuals (early- + late-emerging flies) and using late-emerging individuals only (i.e, excluding emergence data before day 14). Data were subjected to one-way analysis of variance (SAS Institute 1985), and 
least significant difference values $(P=0.05)$ were calculated.

Adult Phenology. These studies were conducted at Scaly Mountain from 1987 to 1990 and at the Mountain Horticultural Crops Research Station (Fletcher, NC) in 1987. Cabbage has been an important commercial crop at the Scaly Mountain location for $>75 \mathrm{y}$, and $\approx 200$ ha were concentrated within a $25-\mathrm{km}^{2}$ area during this study period. At the Fletcher site, cole crops were only grown in small research plots.

Adult flight activity was monitored in cabbage fields with two or three water-pan traps placed in the outer five rows of each field. Plastic pans (18 $\mathrm{cm}$ diameter by $5 \mathrm{~cm}$ deep) were painted fluorescent yellow (No. 2306 John Deere Yellow, Kurfees Coatings, Louisville, KY) to attract $D$. radicum flies (Finch \& Skinner 1974) and filled with soapy water. Traps were placed in fields in mid- to late March, and flies were removed at approximately weekly intervals until December. All anthomyiid flies were identified to species based on the length of the pre-alar bristle (Brooks 1951). Data were converted to number of flies per trap per day, totaled for the season, and expressed as percentage relative abundance (i.e., percentage of total catch).

To observe the spring emergence pattern of flies in the field, $\approx 200$ pupae were collected in early March 1989 from soil surrounding decaying cabbage roots at Scaly Mountain. Pupae were buried in the soil at a depth of $\approx 6 \mathrm{~cm}$, and emergence cages (Throne \& Eckenrode 1985) were placed over the pupae. Emerged flies were removed from cages at approximately weekly intervals, and all anthomyiid flies were identified to species. Soil temperatures adjacent to cages ( 6 $\mathrm{cm}$ depth) were recorded using a temperature recorder (Dickson Company, Addison, IL). Temperature data were also collected in the same manner at the Fletcher site in 1987. To aid the interpretation of field data, degree-day (DD) accumulations were calculated so that discrete generations of flies could be distinguished. Heat units were calculated (daily mean temperature base temperature) using $6.1^{\circ} \mathrm{C}$ as the base temperature, previously reported for $D$. radicum populations in Wisconsin (Eckenrode \& Chapman 1971).

\section{Results}

Survey of Early- and Late-Emerging Biotypes. Percentage early emergence (emergence by 14 d) of flies at $20^{\circ} \mathrm{C}$ from pupae collected during the winter months and held at $4^{\circ} \mathrm{C}$ for $16 \mathrm{wk}$ is shown in Table 1. Emergence of Fletcher populations was similar in 1987 and 1988, with 71 and $76 \%$ early emergers, respectively, and median time for emergence $\left(T_{50}\right)$ ranged from 11 to $12 \mathrm{~d}$ and spread of emergence ( $\left.T_{10-90}\right)$ from 19 to $24 \mathrm{~d}$. At the Scaly Mountain location, the percentage
Table 1. Emergence of $D$, radicum flies from pupae collected in December of various years, held at $4^{\circ} \mathrm{C}$ for 100 d, and then placed at $20^{\circ} \mathrm{C}$

\begin{tabular}{|c|c|c|c|c|c|}
\hline Population & $\begin{array}{c}\mathrm{Yr} \\
\text { collected }\end{array}$ & $n$ & $\begin{array}{c}\text { \% Early } \\
\text { emergers }\end{array}$ & $T_{50}^{b}$ & $T_{10-90^{c}}$ \\
\hline NC (Fletcher) & $\begin{array}{l}1987 \\
1988\end{array}$ & $\begin{array}{r}209 \\
91\end{array}$ & $\begin{array}{l}71 \\
76\end{array}$ & $\begin{array}{l}11 \\
12\end{array}$ & $\begin{array}{l}24 \\
19\end{array}$ \\
\hline NC (Scaly Mountain) & $\begin{array}{l}1987 \\
1988 \\
1989 \\
1990\end{array}$ & $\begin{array}{r}119 \\
359 \\
75 \\
123\end{array}$ & $\begin{array}{l}75 \\
63 \\
44 \\
49\end{array}$ & $\begin{array}{l}12 \\
13 \\
15 \\
18\end{array}$ & $\begin{array}{l}24 \\
26 \\
36 \\
40\end{array}$ \\
\hline NY (Geneva) & $\begin{array}{l}1987 \\
1988 \\
1989\end{array}$ & $\begin{array}{l}373 \\
122\end{array}$ & $\begin{array}{l}95 \\
71 \\
90\end{array}$ & $\begin{array}{l}10 \\
12\end{array}$ & $\begin{array}{r}4 \\
18 \\
6\end{array}$ \\
\hline NY (Highland) & $\begin{array}{l}1989 \\
1987 \\
1989\end{array}$ & $\begin{array}{r}136 \\
43\end{array}$ & $\begin{array}{l}98 \\
93\end{array}$ & $\begin{array}{l}10 \\
10 \\
11\end{array}$ & $\begin{array}{l}6 \\
3 \\
4\end{array}$ \\
\hline
\end{tabular}

a \% Early emergers $=$ percentage emergence by day 14 .

${ }^{b} \mathrm{~T}_{50}$, median day of emergence. tion.

${ }^{C} T_{10-90}$, spread of emergence of 10 and $90 \%$ of the popula-

of early-emerging flies decreased from $75 \%$ in 1987 to $49 \%$ in 1990 , and this decrease was accompanied by increases in both $T_{50}$ and $T_{10-90}$ values.

With the exception of 1988 populations from Geneva, all New York populations consisted of $\geq 90 \%$ early emergers. In these latter populations, median time for emergence was $10-11 \mathrm{~d}$, and the spread of emergence was 3-6 d. Emergence statistics for the 1988 Geneva population (71\% early emergers, $\mathrm{T}_{50}=12 \mathrm{~d}$ and $\mathrm{T}_{10-90}=24$ d) were similar to those of 1987 Scaly Mountain and 1987 and 1988 Fletcher populations.

Inheritance of Early and Late Emergence. Results from crosses of early- and late-emerging individuals indicated that the different rates of fly emergence after the completion of diapause development observed in the Scaly Mountain population were heritable (Table 2). E male $\times \mathrm{E}$ female crosses yielded predominately early emergers $(74 \%)$, significantly higher than the percentage of early emergers from L male $\times \mathrm{L}$ female crosses $(17.3 \%)$. The same trend was observed for median time $\left(T_{50}\right)$ and spread $\left(T_{10-90}\right)$ of emergence, in which values for $\mathrm{E}$ females $\times \mathrm{E}$ males were significantly different from those for $\mathrm{L}$ males $\times \mathrm{L}$ females. Percentage early emergers from crosses of $E$ males $\times \mathrm{L}$ females and $\mathrm{L}$ males $\times \mathrm{E}$ females were 53.9 and $38.4 \%$, respectively, which did not differ from those of $\mathrm{E} \times \mathrm{E}$ or $\mathrm{L} \times \mathrm{L}$ crosses. In addition, in all crosses males emerged before the females (Fig. 1).

Emergence statistics for the late emergers only (i.e., excluding emergence data before day 14) indicated that late-emerging flies from $\mathrm{L} \times \mathrm{L}$ crosses emerged significantly later and emergence was more protracted compared with flies from $E \times E$ crosses. Emergence statistics for $E \times$ $L$ and $L \times E$ crosses did not differ from one another and were of intermediate level compared with $\mathrm{E} \times \mathrm{E}$ and $\mathrm{L} \times \mathrm{L}$ emergence data. 
Table 2. Emergence statistics (at $20^{\circ} \mathrm{C}$ ) of $F_{1} D$, radicum flies produced from various crosses of early (E)- and late (L)-emerging biotypes

\begin{tabular}{|c|c|c|c|}
\hline $\begin{array}{c}\text { Parental } \\
\text { cross }\end{array}$ & $\begin{array}{c}\text { \% Early } \\
\text { emergers }^{a}\end{array}$ & $\begin{array}{c}\mathrm{T}_{50} \\
( \pm \mathrm{SEM})^{b}\end{array}$ & $\mathrm{~T}_{10-90}( \pm \mathrm{SEM})^{c}$ \\
\hline $\begin{array}{l}\text { Early + late emergers } \\
\text { Ed } \times \text { E } \\
\text { Ed } \times \text { L } \\
\text { Lo } \times \text { Eq } \\
\text { Lo } \times \text { Lq }\end{array}$ & $\begin{array}{l}74.0(11.0) \mathrm{b} \\
53.9 \quad(3.0) \mathrm{ab} \\
38.4(11.1) \mathrm{ab} \\
17.3(4.8) \mathrm{a}\end{array}$ & $\begin{array}{l}15.9(2.2) \mathrm{a} \\
23.2(0.8) \mathrm{ab} \\
28.1(3.8) \mathrm{bc} \\
38.1(2.0) \mathrm{c}\end{array}$ & $\begin{array}{l}15.3(4.8) \mathrm{a} \\
31.8(1.1) \mathrm{b} \\
25.5(3.3) \mathrm{ab} \\
35.0(5.7) \mathrm{b}\end{array}$ \\
\hline $\begin{array}{l}\text { Late emergers } \\
\mathrm{E} d \times \mathrm{E} q \\
\mathrm{E} \delta \times \mathrm{L} q \\
\mathrm{~L} d \times \mathrm{E} q \\
\text { Lo } \times \mathrm{L} q\end{array}$ & $\begin{array}{l}- \\
- \\
-\end{array}$ & $\begin{array}{l}33.8(1.3) \mathrm{a} \\
38.6(0.4) \mathrm{ab} \\
38.9(1.6) \mathrm{b} \\
44.6(1.6) \mathrm{c}\end{array}$ & $\begin{array}{l}7.3(2.4) \mathrm{a} \\
10.5(1.3) \mathrm{ab} \\
11.8(1.4) \mathrm{ab} \\
14.3(0.5) \mathrm{b}\end{array}$ \\
\hline
\end{tabular}

Numbers in the same column followed by the same letter are not significantly different $(P<0.05$; least significant differences test). Statistics for early + late emergers are $\mathrm{df}=3,16 ; P<0.05$; and $F=4.87$ (\% early emergers), $13.0\left(\mathrm{~T}_{50}\right)$, and $4.10\left(\mathrm{~T}_{10-90}\right)$. Statistics for late emergers are $\mathrm{df}=3,14 ; P<0.05 ;$ and $F=9.98\left(\mathrm{~T}_{50}\right)$ and $4.90\left(\mathrm{~T}_{10-90}\right)$.

$a$ Early emergers = percentage emergence by day 14.

${ }^{b} \mathrm{~T}_{50}$, median day of emergence.

${ }^{c} T_{10-90}$, spread of emergence of 10 and $90 \%$ of the population.

Adult Phenology. Yellow water-pan trap catches at Scaly Mountain from 1987 to 1990 (Fig. 2) showed that flies began to emerge from overwintered pupae in late March to early April, with a peak catch occurring in mid- to late April of each year. In 1987 and 1989, the initial peak

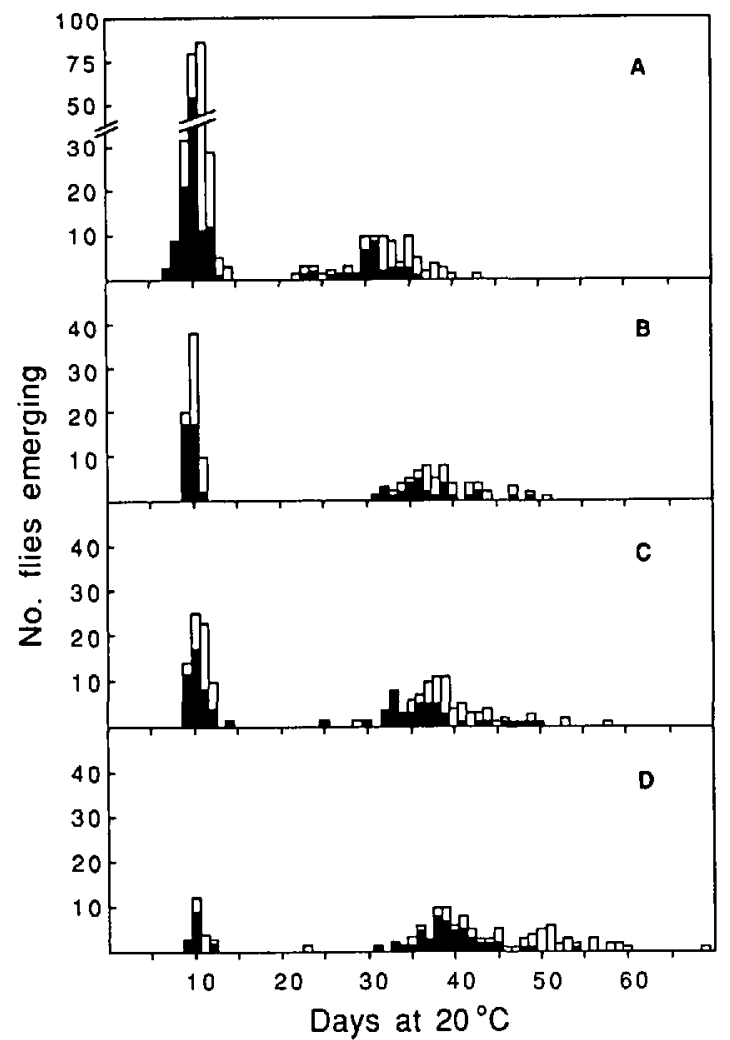

Fig. 1. Emergence at $20^{\circ} \mathrm{C}$ of $F_{1} D$. radicum flies (males, solid bars; females, open bars) produced from

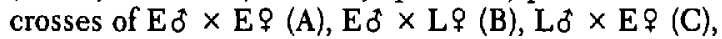
and $\mathrm{L} \delta^{\prime} \times \mathrm{L} q(\mathrm{D})$ emerging biotypes. Before placement at $20^{\circ} \mathrm{C}$, progeny were reared under diapauseinducing conditions and stored at $4^{\circ} \mathrm{C}$ for $16 \mathrm{wk}$. was followed by a 2 to 3 wk period of low catches, and numbers then increased again in late May to early June. This is in contrast to population trends in 1988 and 1990, when April peaks were relatively small and there were not large decreases in catches after the first peak. In all years there appeared to be a third peak within 2 to $3 \mathrm{wk}$ after the second peak, but this catch varied in intensity from year to year. The peak occurring in late May to early June produced the highest early-season trap catches in all years.

An interval of inactivity extending from late June-early July through mid- to late September was observed in all years. As temperatures decreased in the autumn, flies again emerged and were active through early December in 1988, late November in 1987 and 1989, and early November in 1990. In all years except 1990, trap catches in the autumn months exhibited a bimodal pattern.

Emergence of flies in the field from pupae buried under cages in the spring of 1989 at Scaly Mountain is shown in relation to adult flight trends, as measured by water-pan trap catches of flies, in Fig. 3. There was a bimodal pattern of fly emergence from cages, with a peak during early April and a second peak during mid-May; emergence occurred during the early April flight period and the early stages of the second flight period, respectively. The second emergence from cages occurred 198-351 DD after the first emergence was completed, and the interval between the first and second flight peak was 642 DD.

Adult phenology trends at the Fletcher site in 1987 (Fig. 4) were similar to that observed at Scaly Mountain in 1987 in that three distinct peak catches occurred between April and July: a peak in late April, a second small peak in mid- to late May (305 DD after the April peak), and a third large peak in mid-June (705 DD after the April peak). There also existed a peak in late 


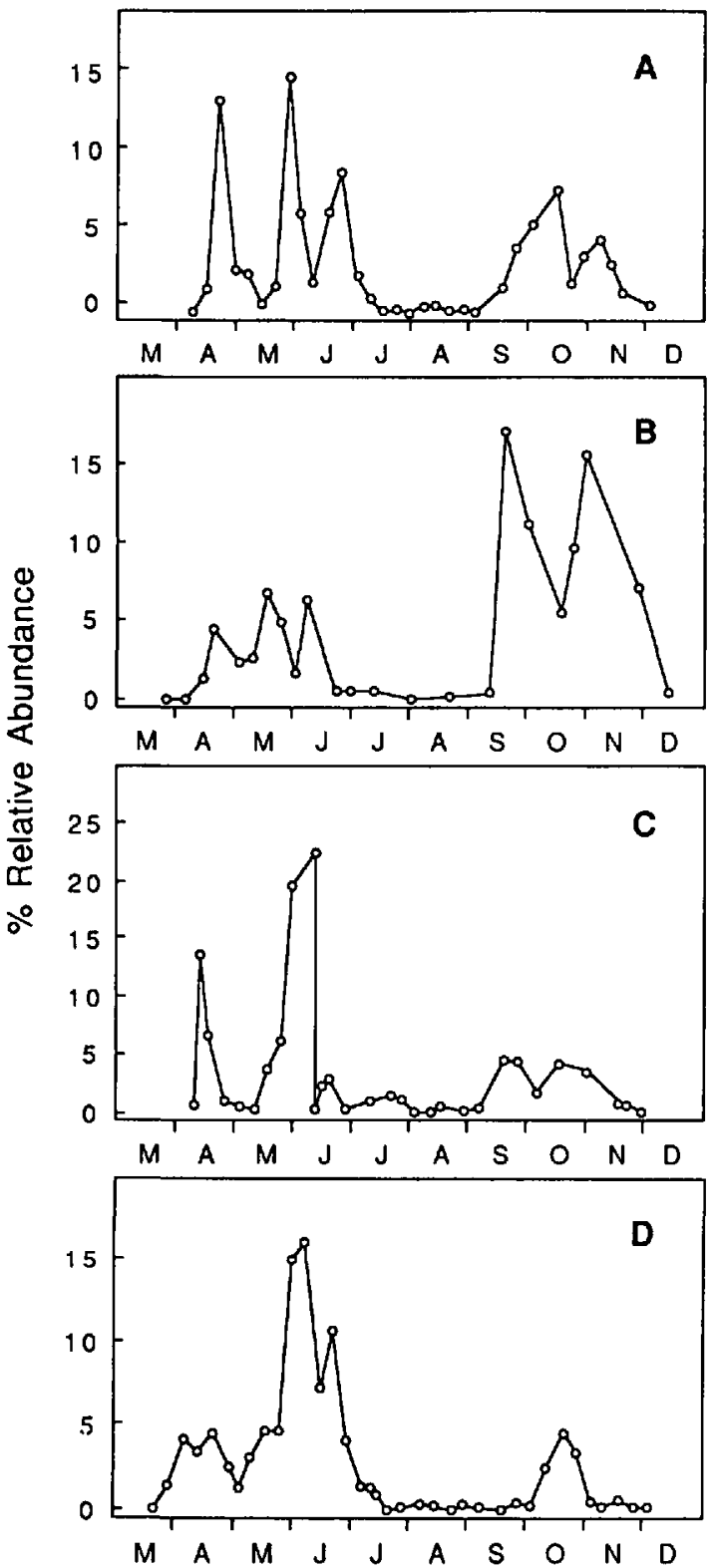

Fig. 2. Seasonal yellow water-pan trap catches of $D$. radicum flies at Scaly Mountain, NC in 1987 (A), 1988 (B), 1989 (C), and 1990 (D).

July, 1,248 DD after the April peak. Fly activity was also suppressed during August and September, and although trap catches increased slightly from late September to November, numbers were generally low during that time.

\section{Discussion}

Delia radicum populations from North Carolina and New York exhibited polymorphism with respect to the timing of fly emergence from overwintered pupae in the spring. New York popula-

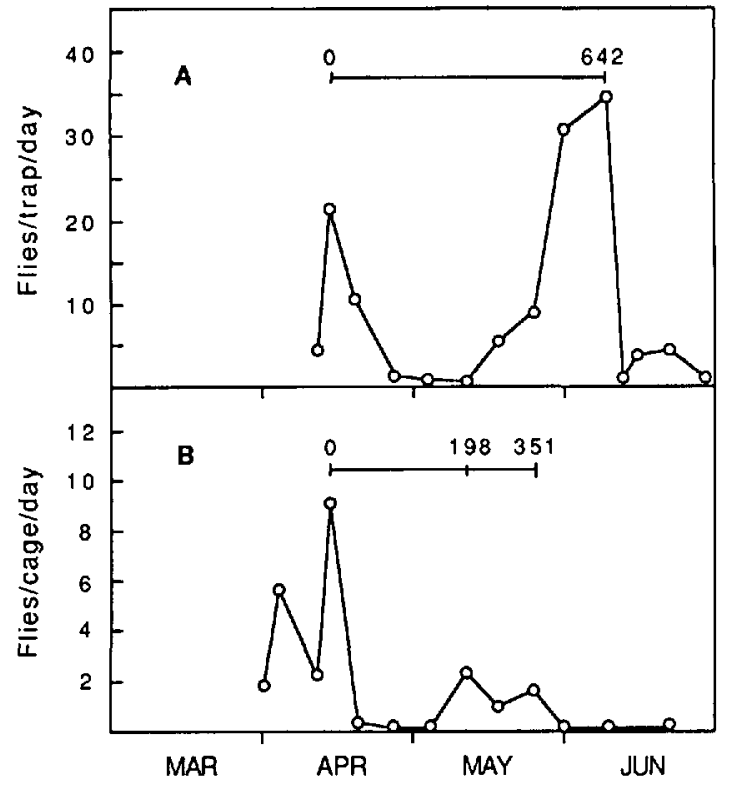

Fig. 3. Yellow water-pan trap catches (A) of D. radicum flies in relation to fly emergence from overwintering pupae buried under emergence cages (B) at Scaly Mountain, NC, in 1989. Numbers along horizontal bars represent DD accumulations using base temperature of $6.1^{\circ} \mathrm{C}$.

tions consisted predominately of early-emerging individuals $(>90 \%)$, which is consistent with previous studies showing three to four discrete generations in that region (Eckenrode \& Arn 1972). However, North Carolina populations consisted of a greater percentage of later-emerging individuals compared with New York populations. The percentage of early emergers in North Carolina populations ranged from 46 to $76 \%$ during the course of this study.

The sympatric occurrence of early and late emergers in North Carolina is also consistent with the results of adult trapping studies. At Scaly Mountain, peak catches of adults that oc-

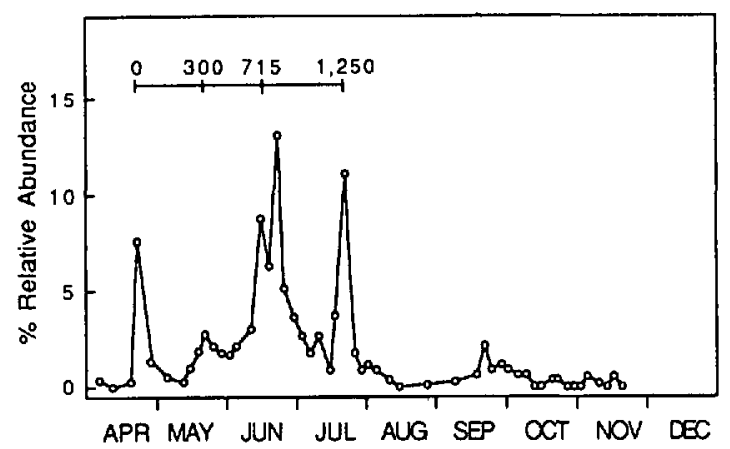

Fig. 4. Seasonal yellow water-pan trap catches of D. radicum flies in 1987 at Fletcher, NC. Numbers along horizontal bar represent $\mathrm{DD}$ accumulations using base temperature of $6.1^{\circ} \mathrm{C}$. 
curred in April of each year were likely the early emergers, the early phase of the second peak (late May-early June of each year) represented late emergers, and the later phase of the second peak represented the second generation of the early biotype. This conclusion is supported by DD accumulations during that time. Accumulation of 198-351 DD that occurred between the last of the early emergers and the late emergers in emergence cages (Fig. 3) was equivalent to $14-25 \mathrm{~d}$ at $20^{\circ} \mathrm{C}$, and most flies emerged between day 30 and 40 (Fig. 1) or 16-26 days after day 14 . Eckenrode and Chapman (1971) previously reported 618 DD necessary for a complete life cycle of $D$. radicum, which was similar to the 642 DD accumulated between the first trap peak and the later part of the second peak (Fig. 2). Although temperature data were not available beyond mid-June, the third water-pan trap peak that occurred in mid- to late June of each year may have represented the second generation of late-emerging adults.

At the Fletcher site, the small adult flight peak $300 \mathrm{DD}$ after the initial peak probably represented late-emerging individuals, and the accumulation of 715 DD between the April and late June peaks was sufficient for completion of an entire generation of the early-emerging biotype. An accumulation of 945 DD between the small May peak and the late July peak was somewhat long for completion of a generation of late emergers, but this may be explained, in part, by the high temperatures $\left(>30^{\circ} \mathrm{C}\right)$ (Eckenrode \& Chapman 1971, Collier \& Finch 1985) during parts of July.

The absence of adult activity from July to September probably represented aestivation of pupae, which is induced by warm temperatures during early stages of pupation (Finch \& Collier 1985). Soil temperatures at the Scaly Mountain location frequently exceeded $26^{\circ} \mathrm{C}$ and often $30^{\circ} \mathrm{C}$ from mid-June through August (J.F.W., unpublished data). The bimodal pattern of trap catches observed in the autumn of 1987, 1988, and 1989 is difficult to explain, but it seems unlikely that this represented separate flight periods of early and late biotypes, because the two biotypes are not known to respond differently to aestivation-inducing or terminating conditions.

In Finch \& Collier's (1983) study, the majority of later-emerging flies from late biotype populations emerged between 50 and $90 \mathrm{~d}$ when held at $20^{\circ} \mathrm{C}$, whereas the majority of later-emerging flies from their intermediate biotype populations emerged between 30 and $50 \mathrm{~d}$. The majority of the later-emerging flies from the Scaly Mountain population also emerged between 30 and $50 \mathrm{~d}$, and the similarity of emergence statistics (percentage of early emergers, $T_{50}$, and $T_{10-90}$ values) between North Carolina populations and those classified as intermediate biotypes in Great Britain (Finch et al. 1986) indicates that D. radi- cum populations in North Carolina are of the intermediate type.

In view of the later emerging characteristics of progeny from the $L \times L$ crosses compared with all other crosses (Fig. 1), it seems possible that a late-emerging biotype could easily evolve from this intermediate biotype if early emergers were removed from the population. However, two important factors appear to be operating to maintain an intermediate biotype in North Carolina. First, summer aestivation presumably acts to terminate temporal isolation of early and later emergers, allowing the two biotypes to interbreed during the autumn months. Resulting progeny then enter diapause during the winter months. Results from crosses between $E$ males $\times \mathrm{L}$ females and $\mathrm{L}$ males $\times$ E females (Fig. 1) showed that progeny from these crosses exhibited an intermediate emergence pattern. Second, the sympatric occurrence of early- and intermediate-emerging biotypes by itself may also deter the selection of a late-emerging biotype. With continued selection for lateness in intermediate biotypes, progeny flies would eventually emerge at the same time as $F_{1}$ early biotypes flies. The simultaneous emergence (and interbreeding) of early- and later-emerging fies would favor the selection of an intermediate biotype.

From 1987 to 1990 , the Scaly Mountain population appeared to shift to a greater percentage of later-emerging individuals. This observation, coupled with the uncharacteristic emergence pattern of the 1988 Geneva population, suggests that the spring emergence pattern of a population is capable of changing over a relatively short period of time. Finch et al. (1986) concluded that weather conditions exert little selection pressure for early or late emergence in England; rather, agricultural practices that affect the availability of host plants were believed to be the primary selection factor.

At the Scaly Mountain location, agricultural practices do not appear to be an important factor in the relative proportion of early- and lateremerging flies. In each year of this study, cabbage (the only commercial cruciferous crop in the area) was panted during the last week of May and the first 2 wk of June, which made this crop available only to the very last of the late emergers and the second generation of the early emergers. Thus, wild cruciferous plants were the only food source available to the entire first generation of early emergers and the vast majority of first-generation later emergers. Barbarea vulgaris R. Br. (yellow rocket or winter-cress) appears to be an important food source for the firstgeneration early and late emergers in that area, as $D$. radicum larvae and pupae are regularly collected from the roots of these plants during May and June (J.F.W., unpublished data).

Year-to-year variation in the percentage of early biotypes at Scaly Mountain (Table 1) may 
be due to the relative number of early- and late-emerging flies present during the autumn months when populations appear to be interbreeding. An abundance of one biotype over the other late in the season could be related to biotic or abiotic mortality factors acting differentially on the two biotypes during the early season when they are temporally isolated. However, little is know regarding the genetics governing earliness or lateness, and the dominance or recessiveness of these traits may also be an important factor.

With the exception of the relatively large peaks of early emergers in April of 1987 and 1989 at the Scaly Mountain trapping site, these earlyseason population trends were similar to what Fulton (1942) observed from 1937 to 1939 in North Carolina. He described a protracted pattern of fly emergence in the spring, beginning in late March-early April and reaching maximum numbers in late May. The site of Fulton's (1942) observations (Glenville, NC) is $\approx 30 \mathrm{~km}$ from Scaly Mountain, and the two sites are separated by forested mountains; therefore, these two populations are geographically isolated. Thus, the $D$. radicum population he observed may have been a predominately intermediate-emerging biotype or, alternatively, during the past $40 \mathrm{yr}$ North Carolina populations have shifted to a greater percentage of early emergers. Regardless, the sympatric occurrence of both early- and lateemerging $D$. radicum flies in the higher elevations of North Carolina makes cruciferous crops susceptible to attack for a relatively long period of time during the spring (April through midJune) and also reduces the utility of $D$. radicum forecasting models as a method for timing pesticide applications against this pest (Eckenrode \& Arn 1972, Wyman et al. 1977, Pedersen \& Eckenrode 1981, Collier \& Finch 1988). Conversely, forecasting models for $D$. radicum infestations in New York are more useful, because those populations remain predominately as early emergers with well-defined and relatively short activity periods (Eckenrode \& Arn 1972).

These findings underscore the necessity for clarification of pertinent field behavior of pests regionally before attempts are made to fine-tune pest management strategies. Furthermore, because of the potential for changing emergence patterns within isolated populations of $D$. radicum over relatively short periods of time, continuous monitoring of populations is critical for successful long-term pest management.

\section{Acknowledgments}

We thank Charles Palmer (North Carolina State University) for technical assistance in the field and laboratory. We also thank Stan Finch, (National Vegetable Research Station, Wellesbourne, Warwick, England) Fred Gould, George Kennedy, and John van Duyn
(North Carolina State University) for improving early versions of the manuscript. This research was supported, in part, by the NCSU Faculty Research \& Professional Development Fund and the North Carolina Agricultural Research Service.

\section{References Cited}

Brooks, A. R. 1951. Identification of the root maggots (Diptera: Anthomyiidae) attacking cruciferous crops in Canada with notes on biology and control. Can. Entomol. 83: 109-120.

Collier, R. H. and S. Finch. 1983. Effects of intensity and duration of low temperatures in regulating diapause development of the cabbage root fy (Delia radicum). Entomol. Exp. Appl. 34: 193-200.

1985. Accumulated temperatures for predicting the time of emergence in the spring of the cabbage root Hy, Delia radicum (L.) (Diptera: Anthomyiidae). Bull. Entomol. Res. 75: 395-404.

1988. Forecasting the times of attack of Delia radicum on brassica crops: major factors influencing the accuracy of the forecast and the effectiveness of control. pp. 49-54. In R. Cavalloro \& C. Pelerents [eds.], Progress on pest management in field vegetables, A. A. Balkema, Rotterdam, Netherlands.

Collier, R. H., S. Finch and M. Anderson. 1989. Laboratory studies on late-emergence in the cabbage root fly (Delia radicum). Entomol. Exp. Appl. 50: 233-240.

Eckenrode, C. J. \& H. Arn. 1972. Trapping cabbage maggots with plant bait and allyl isothiocyanate. J. Econ. Entomol. 65: 1343-1345.

Eckenrode, C. J. \& R. K. Chapman. 1971. Effect of various temperatures upon rate of development of the cabbage maggot under artificial conditions. Ann. Entomol. Soc. Am. 64: 1079-1083.

1972. Seasonal adult cabbage maggot populations in the field in relation to thermal unit accumulations. Ann. Entomol. Soc. Am. 65: 151-156.

Finch, S. \& R. H. Collier. 1983. Emergence of flies from overwintering populations of cabbage root fly pupae. Ecol. Entomol. 8: 29-36.

1985. Laboratory studies on aestivation in the cabbage root fly (Delia radicum). Entomol. Exp. Appl. 38: 137-143.

Finch, S. \& G. Skinner. 1974. Some factors affecting the efficiency of water-traps for capturing cabbage root flies. Ann. Appl. Biol. 77: 213-226.

Finch, S., R. H. Collier \& G. Skinner. 1986. Local population differences in emergence of cabbage root flies from south-west Lancashire: implications for pest forecasting and population divergence. Ecol. Entomol. 11: 139-145.

Fulton, B. B. 1942. The cabbage maggot in North Carolina. N. C. Agric. Exp. Stn. Bull. 335: 1-24.

Harris, C. R. \& H. J. Svec. 1966. Mass rearing of the cabbage maggot under controlled environmental conditions, with observations on the biology of cyclodiene-susceptible and resistant strains. J. Econ. Entomol. 59: 569-573.

Harris, C. R., H. J. Svec \& M. K. Mukerii. 1967. A look at old problems-the need for a modern evaluation of old soil insect problems. Proc. North Cent. Branch Entomol. Soc. Am. 22: 47-52.

Metcalf, C. L., W. P. Flint \& R. L. Metcalf. 1962. Destructive and useful insects. McGraw-Hill, New York. 
Pedersen, L. H. and C. J. Eckenrode. 1981. Predicting cabbage maggot flights in New York using common wild plants. N. Y. Food Life Sci. Bull. 87. SAS Institute. 1985. SAS users guide: statistics. SAS Institute, Cary, NC.

Schoene, W. J. 1916. The cabbage maggot: its biology and control. N. Y. State (Cornell) Agric. Exp. Stn. Bull. 78.

Sears, M. K. \& C. P. Dufault. 1986. Flight activity and oviposition of the cabbage maggot, Delia radicum (Diptera: Anthomyiidae), in relation to damage to rutabagas. J. Econ. Entomol. 79: 54-58.
Throne, J. E. \& C. J. Eckenrode. 1985. Emergence pattern of the seedcorn maggot, Delia platura (Diptera: Anthomyiidae). Environ. Entomol. 14: 182-196.

Wyman, J. A., J. L. Libby \& R. K. Chapman. 1977. Cabbage maggot management aided by predictions of adult emergence. J. Econ. Entomol. 70: $327-331$.

Received for publication 7 July 1992; accepted 16 November 1992. 